\title{
Methodological Study to Develop Standard Operational Protocol on Intravenous (IV) Drug Administration For Children and to Assess its Implication
}

\section{Bijarania SK' ${ }^{\text {, Saini SK}}{ }^{2}$, Verma S $^{3}$}

\begin{abstract}
Introduction: Medicine administration forms a major part of the registered nurse's role. Medicines are prescribed by a physician and dispensed by the pharmacist but responsibility for correct administration rests with the registered nurse. Fatal consequences have been noted following wrong drug, dose, diluent and unsterile technique. The objective of this study was to develop standard operational protocol (SOP) on Intravenous (IV) drug administration and checklist to assess the implementations of the developed SOP. Material and Methods: A methodological research design was adapted to carry out the study. Medicine wards (4-B, 4-C, 5-B and 5-C), Emergency room, PICU at Advanced Paediatric Centre (APC) of Post Graduate Institute of Medical Education and Research (PGIMER), Chandigarh. Thirty observations of IV drug administration and 58 bedside nurses working during JulySeptember 2015. A prospective methodological study was performed to generate SOP. Total 17 FGDs were conducted and data was analysed with SPSS (Version-20.0). Results: The Content Validity Index (CVI) of SOP and checklist was $99.77 \%$ that means all items in both SOP and checklist are valid. Cronbach's-alpha was calculated to assess Internal Consistency of checklists. Over-all standardized Cronbach's alpha was calculated 0.94 that means all items in the checklist are internally consistent and contributing to the total reliability of the checklist. All the nurses felt that SOP is useful. Conclusion: Valid and feasible SOP for drug administration to children through IV route along with valid and reliable checklist was developed. It is recommended to use this document for drug administration for children.
\end{abstract}

Key words: Intravenous, Nurses, Delphi-technique, CVI, FGD

\section{Introduction}

tandard Operating Protocols (SOPs) are written documents $\checkmark$ showing the steps of activities, necessary to complete tasks according to institutional policies ${ }^{1}$. In a Health care institute SOPs advocate the step-by-step performance of any procedure required to provide care to the patients by a trained staff ${ }^{2}$. It is a helpful written document for newly recruited care providers to perform their expected services in that set-up ${ }^{3}$.
${ }^{1}$ Sunil Kumar Bijarania, Nursing Officer, Neonatology, ${ }^{2}$ Sushma Kumari Saini, Lecturer, National Institute of Nursing Education, ${ }^{3}$ Sanjay Verma, Associate Professor, Paediatric Medicine, Advanced Paediatric Centre. All from the Post Graduate Institute of Medical Education and Research, Chandigarh 160012, India.

\section{Address for correspondence \\ Sunil Kumar Bijarania \\ \#239/1, sector 55, \\ Chandigarh 160055, India. \\ Tel No; +919478018928 \\ E-mail-sunnniii@yahoo.com}

Acknowledgements: We thank Dr. Sandhya Ghai, principle, NINE to allow us to undertake this study and Dr. Sunit Singhi, head of paediatrics to permit us to complete this study in the medicine wards APC, PGIMER, Chandigarh. The author also appreciates the cooperation of bedside nurses and Delphi panelists for the study. We would also extend our gratitude to Dr. Sushma Kumari Saini for providing language help in writing and proof reading the article and Miss Sara to make audio recording of all FGDs.

Funding: Nil

Conflict of Interest: This study was conducted at Advanced Paediatric Center (APC), PGIMER, Chandigarh to develop SOP for drug administration for children admitted at APC, PGIMER, Chandigarh.

Permission from IRB: Yes

How to cite

Bijarania SK, Saini SK, Verma S. Methodological Study to Develop Standard Operational Protocol on Intravenous (IV) Drug Administration For Children and to Assess its Implication. J Nepal Paediatr Soc 2017;37(2):153-158.

doi: http://dx.doi.org/10.3126/jnps.v37i2.17170

This work is licensed under a Creative Commons Attribution 3.0 License. 
Intravenous drug administration is the facilitation of safe and effective administration of medicine and fluid to neonate/ infant/ toddler/ preschool/schoolgoing. Fatal consequences have been noted following wrong drug, dose, diluent and unsterile techniques ${ }^{4-6}$. Nurses are chief participant in drug administration and accountable for correct drug administration in their assigned patients ${ }^{7,8}$. Large numbers of drugs are used in Paediatric Medicine ward according to the severity of child's disease condition. The availability of SOPs for drug administration in such wards can make a difference in patient's prognosis ${ }^{9-13}$. In Medical Ward, APC, PGIMER, no such document is noted in respect to drug administration. As per author's knowledge none of other institute in India has a documented well-developed SOPs for drug administration in paediatric wards. The need for a well-developed drug administration protocol for reducing the errors in drug administration is must in tertiary care centres such as PGIMER, Chandigarh. Therefor the present study aimed to provide evidencebased literature for health care providers to help themselves at the time of drug administration.

\section{Material and Methods}

Methodological research design was adapted to develop SOP on IV drug administration for children, admitted in Advanced Paediatric Centre (APC), Post Graduate Institute of Medical Education and Research (PGIMER), Chandigarh. Institutional ethical committee PGIMER, Chandigarh approved the study protocol. Permission to conduct the study was also obtained from the respective authority of the department. Researcher himself approached all the participants and briefly explained the purpose of the study. Informed written consent was obtained from all participants before commencement of the study. Participant's confidentiality was maintained.

The data was analyzed by SPSS software (Version-20.0). Cronbach's-alpha was calculated to assess Internal Consistency of checklists. The overall Cronbach's-alpha value of checklists was 0.947 . Table1 (Part-1 \& 2) shows, when corrected item to total correlation was applied on 43 items of tool, 41 items had item score to total score correlation between 0.20.953 whereas 2 items in the tool had item score to total score correlation $<0.2$ showing their incompatibility with the overall tool. When the individual item was deleted the value of Cronbach's-alpha was increased for 8 items including one item whose score to total score correlation was $<0.2$. That means these 8 items were not contributing to the total reliability of tool and could be discarded. The results were discussed with Delphi panelists; all members were in the favor of keeping all items because they were also equally important in SOP even if the low correlation indicated in the individual item score.

\section{Results}

Valid and feasible SOP for IV drug administration for children along with valid and reliable checklist was developed. For ready references SOP in the form of booklet and poster's binder carrying pictures of drug administration technique were made available to all medicine units of APC, PGIMER, Chandigarh.

\section{Inclusion Criteria Phases of research project}

1. Preparation Phase: Preliminary draft of SOP and checklist was generated in the following four steps (a) Assessment of The Current Practices, (b) Literature was reviewed related to standard care practices of IV drug administration, (c) Ten Focus Group Discussions (FGDs) were conducted and (d) Consultation with specialists of Pediatric Nursing and Pediatric Medicine, incorporating the results of assessment of current practices and valuable suggestions of bed side nurses' gathered in FGDs.

Nurses who gave consent to participate in this study were involved.
2. Validation Phase: Delphi technique was applied for the assessment of content validity of preliminary draft. The Delphi panel included 13 members from the field of Pediatric Medicine and Nursing. Total four rounds were conducted to develop the SOP.

3. Pilot Study (Ist Tryout): conducted after third round of validation that revealed that the existing pictures in the protocol were not clear. The final fourth SOP draft was prepared by replacing existing pictures in protocol with clear and afresh pictures. Content Validity Index (CVI) of SOP and Checklist for all items was calculated $99.77 \%$ after fourth round.

4. Checking The Reliability (II ${ }_{n d}$ Tryout): was performed at Medicine units (4-B, 4-C, 5-B and 5-C), Emergency and PICU, APC, PGIMER, Chandigarh. Researcher observed 30 procedures of IV drug administration during second and third week of September 2015.

5. Evaluation: seven FGDs were conducted to get reviews of bedside nurses about the usefulness of SOP. 
Table 1: Reliability of checklist on IV drug administration (Part-1) (N=30)

\begin{tabular}{|c|c|c|c|c|}
\hline S.No. & Items & $\begin{array}{l}\text { Scale Mean if } \\
\text { Item Deleted }\end{array}$ & $\begin{array}{l}\text { Corrected Item- } \\
\text { Total Correlation }\end{array}$ & $\begin{array}{l}\text { Cronbach's Alpha } \\
\text { if Item Deleted }\end{array}$ \\
\hline 1 & \multicolumn{4}{|l|}{ Selects appropriate Supplies and Articles to prepare tray } \\
\hline $\mathrm{i}$ & Compartment tray & 4.80 & 0.589 & 0.702 \\
\hline ii & Hand sanitizer & 4.80 & 0.589 & 0.702 \\
\hline iii & Burette (Paediatric Drip set (PD set) & 4.97 & 0.464 & 0.703 \\
\hline iv & Dilution solutions & 4.80 & 0.589 & 0.702 \\
\hline $\mathrm{v}$ & Kidney tray & 5.63 & 0.224 & 0.745 \\
\hline vi & Chlorehexidine/ spirit swabs & 4.80 & 0.589 & 0.702 \\
\hline vii & Clean or sterile gloves (if required) & 5.17 & 0.398 & 0.730 \\
\hline viii & Paper bag & 5.70 & 0.407 & 0.714 \\
\hline ix & Sterile additional pack & 5.47 & 0.471 & 0.706 \\
\hline 2 & \multicolumn{4}{|l|}{ At the time of drug preparation } \\
\hline $\mathrm{i}$ & $\begin{array}{l}\text { Check for any pre-medication before medication } \\
\text { administration }\end{array}$ & 6.20 & $0.187^{*}$ & 0.887 \\
\hline ii & $\begin{array}{l}\text { Asks the parents about any medication allergies and } \\
\text { the child's former responses to drug }\end{array}$ & 6.57 & 0.516 & 0.876 \\
\hline iii & $\begin{array}{l}\text { Opens additional pack and open a sterile syringe } \\
\text { into the opened sterile pad }\end{array}$ & 6.87 & 0.859 & 0.852 \\
\hline iv & $\begin{array}{l}\text { Cleans the cap of vial with spirit swab and let dry the } \\
\text { cap }\end{array}$ & 6.27 & 0.455 & 0.877 \\
\hline$v$ & $\begin{array}{l}\text { Withdraws the needle and syringe and keep them } \\
\text { on sterile pack. }\end{array}$ & 6.87 & 0.859 & 0.852 \\
\hline vi & $\begin{array}{l}\text { Keeps the filled syringe in sterile pack and takes it to } \\
\text { the child without showing the needle }\end{array}$ & 6.87 & 0.859 & 0.852 \\
\hline 3 & At the time of drug administration & & & \\
\hline $\mathrm{i}$ & $\begin{array}{l}\text { Explains the procedure to the child /parents clearly } \\
\text { using appropriate language and take consent from } \\
\text { parents to administer drug to the child }\end{array}$ & 6.33 & 0.473 & 0.877 \\
\hline ii & $\begin{array}{l}\text { Asks the parents about any known medication } \\
\text { allergies }\end{array}$ & 6.37 & 0.326 & 0.886 \\
\hline iii & Keep a dry swab under the cannula hub & 6.77 & 0.721 & 0.861 \\
\hline iv & Cleans the white stopper of cannula & 6.20 & 0.318 & 0.883 \\
\hline $\mathrm{v}$ & Keeps the white stopper on a sterile additional pad & 6.87 & 0.859 & 0.852 \\
\hline vi & $\begin{array}{l}\text { Cleans the cannula hub with squeezed } \\
\text { Chlorehexidine/spirit swab }\end{array}$ & 6.30 & 0.367 & 0.882 \\
\hline vii & $\begin{array}{l}\text { Observes vitals of the child carefully during \& after } \\
\text { administration }\end{array}$ & 12.90 & 0.289 & $0.950^{\star *}$ \\
\hline viii & $\begin{array}{l}\text { Uses divertional technique while administration of } \\
\text { drug to the child }\end{array}$ & 12.73 & 0.543 & 0.946 \\
\hline ix & $\begin{array}{l}\text { Stops injection of the medicine if the child suddenly } \\
\text { becomes lethargic or hyperactive }\end{array}$ & 13.47 & $-0.112^{*}$ & $0.953^{* *}$ \\
\hline
\end{tabular}

Notes: Overall scale mean is 26.50 , Overall reliability is .947 (standardised Cronbach's alpha), * Items in the tool which shows item to total correlation $<0.2,{ }^{* *}$ Items in the tool whose Cronbach's Alpha value increased if Item deleted. 
Table 2: Reliability of checklist on IV drug administration (Part-2) ( $N=30)$

\begin{tabular}{|c|c|c|c|c|}
\hline 1 & Items & $\begin{array}{l}\text { Scale Mean if } \\
\text { Item Deleted }\end{array}$ & $\begin{array}{l}\text { Corrected Item- } \\
\text { Total Correlation }\end{array}$ & $\begin{array}{l}\text { Cronbach's Alpha } \\
\text { if Item Deleted }\end{array}$ \\
\hline $\mathbf{i}$ & Steps for preparation of drug with Burette (PD set) & & & \\
\hline ii & $\begin{array}{l}\text { Opens the burette from sterile packing and hang over } \\
\text { the IV fluid bottle holder }\end{array}$ & 12.80 & 0.953 & 0.940 \\
\hline iii & $\begin{array}{l}\text { Primes the burette tubing with } 15 \mathrm{ml} \text { of infusion } \\
\text { solution }\end{array}$ & 12.80 & 0.953 & 0.940 \\
\hline iv & Fills the prescribed amount of infusion solution & 12.80 & 0.953 & 0.940 \\
\hline $\mathrm{v}$ & $\begin{array}{l}\text { Cleans the drug inducer port on the burette with spirit/ } \\
\text { Chlorehexidine swab and let dry it }\end{array}$ & 12.80 & 0.953 & 0.940 \\
\hline vi & $\begin{array}{l}\text { Injects the prefilled medicine in to the burette and } \\
\text { mixed thoroughly with the IV solution by agitating the } \\
\text { burette several times }\end{array}$ & 12.80 & 0.953 & 0.940 \\
\hline vii & Discards $10 \mathrm{ml}$ solution of primed tubing & 12.80 & 0.953 & 0.940 \\
\hline 2 & Steps for administration of Infusion via Burette (PD & set) & & \\
\hline $\mathrm{i}$ & $\begin{array}{l}\text { Clean the injection port with an alcohol swab and } \\
\text { allow drying it. }\end{array}$ & 12.83 & 0.857 & 0.941 \\
\hline ii & $\begin{array}{l}\text { Insert syringe hub to flush the line with } 2 \mathrm{~mL} \text { normal } \\
\text { saline }\end{array}$ & 12.80 & 0.953 & 0.940 \\
\hline iii & Check the site again for patency & 12.80 & 0.953 & 0.940 \\
\hline iv & $\begin{array}{l}\text { Attach the primed tubing of burette to the } 10 \mathrm{cms} \\
\text { extension or direct to the vein cannula }\end{array}$ & 12.80 & 0.953 & 0.940 \\
\hline $\mathrm{v}$ & $\begin{array}{l}\text { Adjust drip rate to administer the solution at the } \\
\text { prescribed rate by the physician }\end{array}$ & 12.80 & 0.953 & 0.940 \\
\hline vi & Adds $10-15$ NS to flush the drug in drip set & 12.80 & 0.953 & 0.940 \\
\hline 3 & After drug administration to the child & & & \\
\hline $\mathrm{i}$ & $\begin{array}{l}\text { Flushes tubing/cannula with } 5 \mathrm{ml} \text { of normal saline or } \\
\text { running IV fluid }\end{array}$ & 12.93 & 0.474 & 0.947 \\
\hline $\mathrm{ii}$ & $\begin{array}{l}\text { Praises the child/ use non-verbal approach for } \\
\text { cooperation }\end{array}$ & 12.77 & 0.242 & $0.950^{* *}$ \\
\hline iii & $\begin{array}{l}\text { Observes the child for } 15-20 \text { minutes for any } \\
\text { side effects and ask the parents to inform you } \\
\text { any untoward sign/symptoms if appear after drug } \\
\text { administration }\end{array}$ & 13.30 & 0.408 & $0.948^{* *}$ \\
\hline iv & Allow the child to express his or her feeling & 13.27 & 0.371 & $0.950^{\star *}$ \\
\hline $\mathrm{v}$ & Reassures the child that next time will be easier & 13.47 & 0.304 & $0.948^{* *}$ \\
\hline vi & $\begin{array}{l}\text { Stay with child and gives feed back /instruction to the } \\
\text { child/parent if required }\end{array}$ & 13.57 & 0.202 & $0.948^{* *}$ \\
\hline vii & $\begin{array}{l}\text { Reminds/tells the parents about the timings of next } \\
\text { dose }\end{array}$ & 13.57 & 0.202 & $0.948^{* *}$ \\
\hline
\end{tabular}

Notes: Overall scale mean is 26.50 , Overall reliability is .947 (standardised Cronbach's alpha), * Items in the tool which shows item to total correlation $<0.2,{ }^{* *}$ Items in the tool whose Cronbach's Alpha value increased if Item deleted.

\section{Discussion}

SOPs describe the activities necessary to complete tasks according to institutional regulations, provincial laws. These are used to remove variation in procedure performance because every individual develops his/her own concept of procedure's process on scientific basis ${ }^{1}$. Present study was undertaken because no such SOP on IV drug administration notified in APC wards, PGIMER.
Initially the review of literature was done to check the availability of SOPs and checklists for drug administration worldwide. Only national and international literature of SOPs and checklists related to drug administration was not enough to gather sufficient information for development of SOP and checklist. Assessment of current-practices of drug administration was also equally important to know about the regular 
practices of drug administration. In five observations of IV drug administration at APC, PGIMER, Chandigarh, researchers observed that all bedside-nurses followed few steps but few were totally ignored though those steps were also equally important to be performed.

To know the reason of ignorance, a series of FGDs were conducted. The number of FGDs to be conducted depends upon the purpose of study, along with the heterogeneity of group ${ }^{14}$. Another study favors that FGDs should be continued until repetition of themes is not started ${ }^{15}$. During this study, the saturation of information was achieved after 10 FGDs. The size of the group should be of between 6-12 people because large group precludes adequate participation by most members and small group fails to provide significant greater coverage on the topic ${ }^{16}$. In present study all FGDs were conducted with small group of 6-7 members who had 4-5 years of exclusive-experience of pediatric bedside nursing because few guidelines suggest that smaller groups (4-6 members) are allowed when the members have much experience to share ${ }^{16,17}$. On the base of gathered information finally a preliminary draft of SOP and checklist was prepared.

For further refinement in the preliminary draft of protocol and checklist Delphi-technique was used. The Delphi-technique is well suited as a method for consensus building and to establish content validity ${ }^{18}$. Current study had a heterogeneous Delphi panel of 13 experts included seven members of nursing faculty and six faculty members from pediatrics medicine. In a Similar study done by Kaushal et al. Delphi members were eleven ${ }^{19}$. D'Souza et al. used an interdisciplinary panel of seven national and international experts for development of a tool for assessing preterm infants ${ }^{20}$. George et al. had a panel comprised of 10 members $^{21}$.

Delphi-technique employs repeated rounds in which printed drafts of drug administration procedures are given to the Delphi-panelists until a common consensus is reached. In the present study, though the consensus of panelists was achieved after third round but few changes were required after first tryout. To make these changes feasible fourth round was conducted before development of final version of SOP and checklist. In similar studies conducted by Kaushal et al. common consensus was reached in four Delphirounds ${ }^{19}$, according to George et. al. three rounds were sufficient ${ }^{21}$.

The overall CVI of current study from the panel of experts was calculated $99.77 \%$ indicating the validity of the individual item. In a similar study, conducted by D'Souza et al. the overall CVI was $95 \%{ }^{20}$.

The reliability of these Checklists was ensured by Cronbach's alpha to determine the internal consistency or average correlation of items in a survey-instrument to gauge its reliability ${ }^{22}$. The overall Cronbach's alpha value of checklists was 0.947 and item score correlation to overall score was in-betweens 0.2-0.953. In a similar study by George et al. overall value of alpha was $0.76^{21}$. Another study Kaushal et al. revealed Cronbach's alpha value $0.97^{19}$. The corrected item to total correlation was applied upon 43 items of tool, 41 items had item score to total score correlation between 0.2-0.953 whereas two items in the tool had item score to total score correlation $<0.2$ showing their incompatibility with the overall tool. When the individual item was deleted the value of Cronbach's alpha was increased for 8 items including one item whose score to total score correlation was < 0.2 . That means these 8 items were not contributing to the total reliability of tool and could be discarded. The results were discussed with Delphi-panelists; all members were in the favor of keeping all items because they were also equally important in SOP even if the low correlation indicated in the individual item score.

\section{Conclusion}

No institutes in India have documented any welldeveloped SOPs for IV drug administration in paediatric wards. SOP on IV drug administration is established which is valid and feasible along with reliable and valid checklists. It is recommended to use this SOP for IV drug administration for children at all levels (primary, secondary and tertiary). Checklist should be used by nurse administrators to assess the implementation of SOP.

3. Bianca A, Demand M. The Importance of Standard Operating Procedures in Organizations. Houston chronicle, 2014. http://smallbusiness.chron.com/ importance-standard-operating-proceduresorganizations-69530.html (accessed on 10 Nov 2014)

4. Cousins D. Medication errors in intravenous drug preparation and administration: a multicentre audit in the UK, Germany and France. Qual Saf Health Care 2005;14(3):190-5. 
5. Prot SE. Drug administration errors and their determinants in pediatric in-patients. Int J Qual Health Care 2005;17(5):381-9. Epub 2005 Aug 2

6. Kaushal R. Medication Errors and Adverse Drug Events in Pediatric Inpatients. JAMA Pediatr, 2001;285(16):2114.

7. Geake BG, Williams P. Administration of medicines clinical calculations assessment for registered nurses policy. 2012 August; [9 screens) http://www.tsdhc. nhs.uk/publications/TSDHC/Administration $\% 20$ of $\% 20$ Medicines $\% 20-\% 20$ Clinical\%20Calculations $\% 20$ Assessment $\% 20$ for $\% 20$ Registered $\% 20$ Nurses $\% 20$ Policy.pdf (accessed on 10 Nov 2014)

8. Chaboyer W, Murray AM, Wallis M. Standard operating protocol for implementing bedside handover in nursing. centre-health-practice-innovation, 2008;120. http://www.safetyandquality.gov.au/wp-content/ uploads/2012/02/SOP-Bedside-Handover .pdf (accessed on 10 Nov 2014)

9. Tissot E, Cornette C, Limat S, Mourand J, Becker M, Etievent $\mathrm{J}$ et al. Observational study of potential risk factors of medication administration errors. Pharm World Sci 2003;25(6):264-8

10. Chua S, Chua H, Omar A. Drug administration errors in paediatric wards: a direct observation approach. Eur J Pediatr 2009;169(5):603-11. DOI: 10.1007/s00431009-1084-z.

11. Ross L. Medication errors in a paediatric teaching hospital in the UK: five years operational experience. Arch Dis Child 2000;83(6):492-7.

12. Greig L, Sudworth A. Administration of Medications and Fluids via a Peripheral Intravenous Cannula. Scottish Diabetes Research Network, 2013;22(1):1-6. http://www.sdrn.org.uk/?q=node/45_(accessed on 16 Jan 2016)
13. Rao TS, Radhakrishnan R, Andrade C. Standard operating procedures for clinical practice. Indian J Psy 2011;53(1):1. DOI: 10.4103/0019-5545.75542

14. Cameron J. Focusing on the focus group. In: Hay I, ed. Qualitative Research Methods in Human Geography. $2^{\text {nd }}$ ed. Melbourne: Oxford University Press; 2005.

15. Wong LP. Focus group discussion: a tool for health and medical research. Sing Med J 2008;49(3):256-60; quiz 261

16. Krueger RA. Focus Groups: A Practical Guide for Applied Research. 3rd ed. Newbury Park, CA: Sage Publications; 1988.

17. Hsu CC, Sandford BA. The Delphi Technique: Making Sense of Consensus. PARE 2007;12(10):1-8. ISSN 1531-7714.

18. GIL, Beatriz; PASCUAL-EZAMA, David. The Delphi Method as a technique to study Validity of Content. Anales de Psicología / Annals of Psychology [S.I.], v. 28, n. 3, p. 1011-1020, Oct. 2012. ISSN 1695-2294.

19. Kaushal RK, Kapoor S, Kaur S, Bhagat H. A Methodological study to develop a 'Nursing Checklist' for receiving patients in ICUs. Nurse Midwifery Res $J$ 2015;11(1):1-11.

20. D'Souza SRB, Kumar V, Lewis LE. Development of tool for assessing preterm infants. Nurse Midwifery Res J 2014;10(3):91-9.

21. George L, Kaur S, Rao KLN. Development of a Nursing Care Protocol for care of neonates with Esophageal atresia/trachea- esophageal fistula. Nurse Midwifery Res J 2014;10(3):106-19.

22. Tavakol M, Dennick R. Making sense of Cronbach's alpha. Int J Med Educ, 2011;2:53-55. ISSN: 20426372. DOI: 10.5116/ijme.4dfb.8dfd 